\title{
Can Facebook likes predict the purchase probability of electricity storage systems?
}

\author{
Stefan Poier $^{1}$
}

Received: 25 June 2020 / Revised: 9 August 2021 / Accepted: 11 August 2021 / Published online: 23 August 2021

(c) The Author(s) 2021

\begin{abstract}
This study among owners of photovoltaic systems investigates whether users' Big Five personality traits derived from their Facebook likes contribute to whether or not they adopt an electricity storage. It is based on the finding that the digital footprint, especially the Facebook likes, can in part predict the personality of users better than friends and family. The survey was conducted among 159 Facebook users in Germany who owned a photovoltaic system. For comparison, a control sample with data from the German Socio-Economic Panel with 425 photovoltaic owners among 7286 individuals was used. The results show that, for extraversion, agreeableness, and neuroticism, the mean scores could be sufficiently predicted. However, a positive correlation could only be detected for extraversion. The comparison of the user groups could not provide satisfying results. None of the Big Five personality traits could be used to distinguish the two user groups from each other. Although the results did not support the hypotheses, this study offers insights into the possibilities of combining data mining, personality psychology, and consumer research.
\end{abstract}

Keywords Big Five $\cdot$ Renewable energy $\cdot$ Consumer behavior $\cdot$ Social networks $\cdot$ Online marketing

\section{Introduction}

Since people have been on the planet, they have demonstrated a tendency to attempt to classify their fellow human beings. For example, the temperament theory, which has its roots in antiquity, was developed to differentiate individuals according to their different temperaments (Merenda 1987). In modern times, anthropological racial theories as well as personality models can be found (e.g., Banks 1996). In the field of economics, the differentiation of products, markets, and market actors serves to simplify processes and predict certain outcomes. In the field of marketing, it is useful to know whether or not a consumer is likely to purchase a particular productwithout having to ask the consumer. There are several ways to build correlations between user groups and user behavior. For example, collaborative filtering is used by online commerce websites such as Amazon ("People who bought books about statistics were also interested in econometrics"). This method attempts to identify the future behavior of a consumer from his

Stefan Poier

s.poier.125@studms.ug.edu.pl

1 Faculty of Economics, University of Gdansk, Armii Krajowej 119/121, 81-824 Sopot, Poland or her past behavior (Das et al. 2007). Another way is to predict a certain attitude or behavior based on an individual's personality traits. These could be, for example, personal human values or the Big Five personality traits of openness, conscientiousness, extraversion, agreeableness, and neuroticism (Bilsky and Schwartz 1994; Cieciuch and Schwartz 2017; McCrae and Costa 1997, 1999; Schwartz 2017). This approach posits that, if we know an individual's personality traits, we can predict his or her behavior to a certain extent (Aral and Walker 2012). The difficult aspect of this is acquiring valid information about a consumer's personality traits. Since the US presidential election in 2017, there has been growing interest and controversial discussion about whether the US election or the UK's Brexit decision may have been influenced by personalitydriven advertising - so-called micro-targeting. The responsible company, Cambridge Analytica, claimed to have derived the personality profiles of US citizens from their digital footprints, especially their Facebook likes. Although this was a fantastic media headline, it is unclear whether it is true and actually possible to determine the Big Five traits with enough accuracy using likes alone or whether the contribution of likes to users' profiles is sufficient. In marketing and especially in election advertising, it has been a common practice for many years to aggregate and use commercial demographic data to achieve 
a targeted address of the individual. Today, it should be clear that, even in the infamous cases of targeting and using psychometric data in recent years, which have created scandals in the media — due in part to a lack of understanding — not only have the Big Five played a decisive role and not only were Facebook likes used for their calculation (González 2017). However, if individuals in a narrow target group are very similar in their socio-economic variables, it could well be that their individual personal dispositions play the decisive role. This narrow target group exists, for example, among owners of photovoltaic (PV) systems who have to decide whether or not to buy an electricity storage system. Jacksohn et al. (2019) found that e.g., age, income, household size, and education level were significantly different between adopters and non-adopters of PV systems. Therefore, the target group of the present study is very similar in these parameters, and it can be suspected that individual personal dispositions play a greater role in differentiating within this group. Although there exists some literature examining the influence of personality on energy efficiency investments (Busic-Sontic and Brick 2018; Poier 2021), it has never been investigated whether the digital footprint of usersand inferred from this their personality traits-also reveal a contribution about the adoption of electricity storage among owners of PV systems.

The aim of the present article is to narrow this research gap and to investigate if the personality traits of PV users, predicted by their Facebook likes, are suitable for distinguishing between adopters and non-adopters of electricity storage in this target group. This contributes not only to the understanding of consumer behavior but also to the usefulness of data mining in social networks for consumer research. In a first step, it is tested whether the predictions match the users' self-assessments. A second round of research will examine whether PV system owners can be differentiated into adopters and non-adopters of electricity storage based on their personality traits derived from Facebook likes. The remainder of this article is organized as follows: a review of the literature is provided in chapter 2 , followed by an explanation of the methodology, as well as the hypothesis formulation in chapter 3. Data collection and preparation is described in chapter 4 . After that, the results are presented in chapter 5 . This is followed by a discussion of the results and the limitations of the study in chapter 6 . After an outlook on further research, the article ends with the conclusions.

\section{Research background}

Personality traits are a psychological construct used to describe individuals. Assuming a certain stability, this could be useful for describing or even predicting human behavior and, for marketers in particular, purchase behavior. In the scientific literature, a number of definitions of personality traits can be found. DeYoung (2015), for example, described them as "probabilistic descriptions of relatively stable patterns of emotion, motivation, cognition, and behavior, in response to classes of stimuli that have been present in human cultures over evolutionary time." Following John et al. (2010) and Valchev et al. (2013), they are habitual patterns of behavior, thought, and emotion that are stable over time and in comparable situations. What all definitions of personality traits share is "the emphasis on the relative consistency of behavioral predispositions to behave in a particular manner across situations" (Fischer 2018).

Over the last three decades, researchers have developed several frameworks to describe the personalities of individuals using descriptive terms for patterns of behavior with different numbers of dimensions. Eysenck, for example, introduced his PEN model consisting of three elements: psychoticism, extraversion, and neuroticism; this later formed the basis for Costa's and McCrae's NEO personality inventory (Barrett et al. 1998; Parish et al. 1965). In the early 2000s, Ashton and Lee built on the research of Costa and McCrae (2008) and Goldberg (1993) and introduced Honesty-Humility as an additional factor to the five existing traits (Ashton et al. 2004; Ashton and Lee 2007). This sixfactor model is known as the HEXACO model, derived from the initial letters of the factors Honesty-Humility, Emotionality, Extraversion, Agreeableness, Conscientiousness, and Openness to Experience (Ashton and Lee 2009). Although these models exist with more or less than five items, there is a broad consensus in the scientific literature that five-factor models make the greatest explanatory contribution. Thus, the most-often used and best-known models in contemporary research comprise five personality traits or personality factors. They are known as five-factor models (FFM) or the Big Five (Goldberg et al. 2006; McCrae and Costa 1999; McCrae and John 1992). Costa and McCrae identified neuroticism, extraversion, and openness to experience as three factors of 16 in a first step (Costa and McCrae 1976). Some years later, they added agreeableness and conscientiousness to the model, which later became known as the NEO-Personality Inventory Revised (NEO PI-R) after several improvements (Costa and McCrae 2008). The five traits can be measured with a number of inventories such as the original 44-item Big Five Inventory (BFI) (Benet-Martínez and John 1998), the revised 60-item version BFI-2 (Soto and John 2017), the 60-item NEO-FFI (McCrae and Costa 2004), and the 240-item NEO-PI-R (Costa 1996; Costa and McCrae 2008). Table 1 shows the five factors, each one comprising six facets.

Numerous studies demonstrate the contribution of personality traits to behavior (Busic-Sontic and Brick 2018; Danielsbacka et al. 2019; Poier 2021; Rozgonjuk et al. 2021; Zhang et al. 2021). A recent study of Chinese students found that their information-seeking behavior depended 
significantly on their personality traits. Among other things, information seeking can reduce perceived risk in purchasing - a core construct of buyer behavior (Zhang et al. 2021). Thus, there is evidence of a contribution of personality traits on consumer behavior. Busic-Sontic and Brick (2018) and Poier (2021) investigated the direct and indirect effects of the Big Five on energy efficiency installations and photovoltaic adoption, respectively. In both studies, the effects were weak, but the Big Five were also opposed to very heterogeneous socio-demographic significant control variables.

The possibility of drawing conclusions about the personality traits of users of social media platforms, especially Facebook, from their profiles has been studied and confirmed in several studies (Kosinski et al. 2016; Kosinski 2021; Marengo et al. 2020; Marouf et al. 2020b; Segalin et al. 2017; Youyou et al. 2015). One of the most popular articles in recent years has been that of Youyou et al. (2015). In their study, they looked at inferring the personality of users from their Facebook profiles and found that a user with more than 10 likes can be better described by his Facebook profile than by the work colleagues and that more than 300 likes can describe the user better than his or her spouse. Segalin et al. (2017) were able to draw conclusions about the personality traits of Facebook users from their profile photographs. In contrast, Marengo et al. (2020) examined differences in personality traits between users of social media platforms and between users and non-users. They found that above all extraversion of social media users was significantly higher than that of non-users.

\section{Methodology and hypotheses}

The aim of this study is to explore whether consumers' digital footprints - their Facebook likes, in particular-are suitable for predicting their purchase probability of a solar electricity storage system in Germany. Based on the literature introduced in chapter 2 , the research question derived from this is as follows:

Is it possible to make a prediction about an owner of a photovoltaic system's adoption of an electricity storage system using only the predicted Big Five personality profile derived from Facebook likes?
To answer this question, two hypotheses were tested:

- H1: The predicted Big Five personality traits resulting from Facebook likes are significantly equivalent to the Big Five personality traits that emerge from self-reports.

- H2: The Big Five personality traits between adopters and non-adopters of electricity storage systems are significantly different.

These considerations are based on the assumption that the sum of the users' activities reflects their online behavior, from which in turn their personality traits can be derived (Kosinski et al. 2016; Marouf et al. 2020a; Youyou et al. 2015). In this study, an online prediction application programming interface (API) provided by the Psychometrics Centre of the University of Cambridge is used as the basis for data processing (Popov et al. 2015). The developers of the API collected data about the participants' personality traits and their Facebook likes and calculated correlations between their Facebook usage behaviors and personalities that could also be used the other way around-that is, to predict behavior based on personality (Kosinski et al. 2013).

For the first hypothesis, predictions provided by Apply Magic Sauce (AMS) (www.applymagicsauce.com) will be used as the source of comparison. AMS is an online prediction service provided free of charge for academic purposes by the Psychometrics Centre of the University of Cambridge (Kosinski et al. 2019). It uses data from the myPersonality project (www.myPersonality.org), a Facebook app that was active from 2007 until 2012 and used by approximately 6 million users. About $30-40 \%$ of the participants donated their Facebook data voluntarily. To draw relations between a psychological assessment and Facebook pages that were liked by the participants, personality predictions are based on opt-in data from 260,000 participants who completed the 100-item International Personality Item Pool (IPIP) questionnaire in English (Popov et al. 2015; Stillwell and Kosinski 2019). The app was banned by Facebook in 2019, although it hasn't been active since 2012. Unfortunately, the availability of the myPersonality dataset has since been discontinued following several concerns regarding data protection. Thus, it is no longer possible to derive raw scores from the AMS results. AMS provides results for the estimated

Table 1 Big Five personality traits according to the NEO-FFI. Source: McCrae and Costa (1999)

\begin{tabular}{ll}
\hline Personality traits & Personality trait facets \\
\hline Openness to experience & Fantasy, aesthetics, feelings, actions, ideas, values \\
Conscientiousness & Competence, order, dutifulness, achievement striving, self-discipline, deliberation \\
Extraversion & Warmth, gregariousness, assertiveness, activity, excitement seeking, positive emotions \\
Agreeableness & Trust, straightforwardness, altruism, compliance, modesty, tender mindedness \\
Neuroticism & Anxiety, hostility, depression, self-consciousness, impulsiveness, vulnerability \\
\hline
\end{tabular}


results not as absolute scores but as percentiles. Both selfreports and predictions will be converted into $z$-scores in advance in order to achieve a common base for $t$ tests.

\section{Data}

Data were collected through an online survey between April and June 2019. The questionnaire contained items regarding household and personal demographics, technical features of the PV system, and information about a possibly existing battery. In addition, it included two question batteries about psychological traits. The first block, concerning the Big Five personality traits, was mandatory and comprised 16 items that were taken directly from the SOEP questionnaire (Goebel et al. 2019). Prior to the online questionnaire, participants declared themselves to be of legal age and to be taking part voluntarily. After being provided with detailed information about data protection and the scientific use of personal data, all participants gave their written consent to the use of their data and information about the privacy policy associated with the survey. Facebook carefully reviewed the app and, finally, after a few months of coordination and negotiation, allowed its use for scientific purposes and activated the app. This Facebook app is the key element of the present study (Fig. 1). It enabled the data exchange between Facebook and AMS for data processing and the calculation of the predictions.

Because the target group comprised Facebook users who were also owners of a PV system, the study was advertised directly on Facebook and addressed individuals who were interested in solar power, photovoltaics, renewable energies, and related topics. In addition, a call to participate in the study was posted in relevant groups with a total of about 26,566 members. During the period, in which the survey was conducted, it was not only the Europe-wide introduction of the General Data Protection Regulation that was omnipresent. At the same time, several data-related scandals in connection with the Facebook platform became public. The result was an unexpectedly low participation rate since it was actually to be assumed that a technology-savvy target group within the platform, of which they are users, would show more activity. The reactions to the advertising or postings to the study were largely characterized by hostile rejection, including insults and insinuations. These, too, were unexpected because the target group should have comprised higher-earning and better-educated people, and a higher share of married couples (Table 12 in the Appendix). It was
Fig. 1 Login to the likeexchange app. Note: Figure presents the login screen to the Facebook app. The user must consent in advance to his likes being accessed. After proceeding, the user's likes were transferred to the AMS-API and processed. The resulting Big Five traits were re-transferred as percentiles

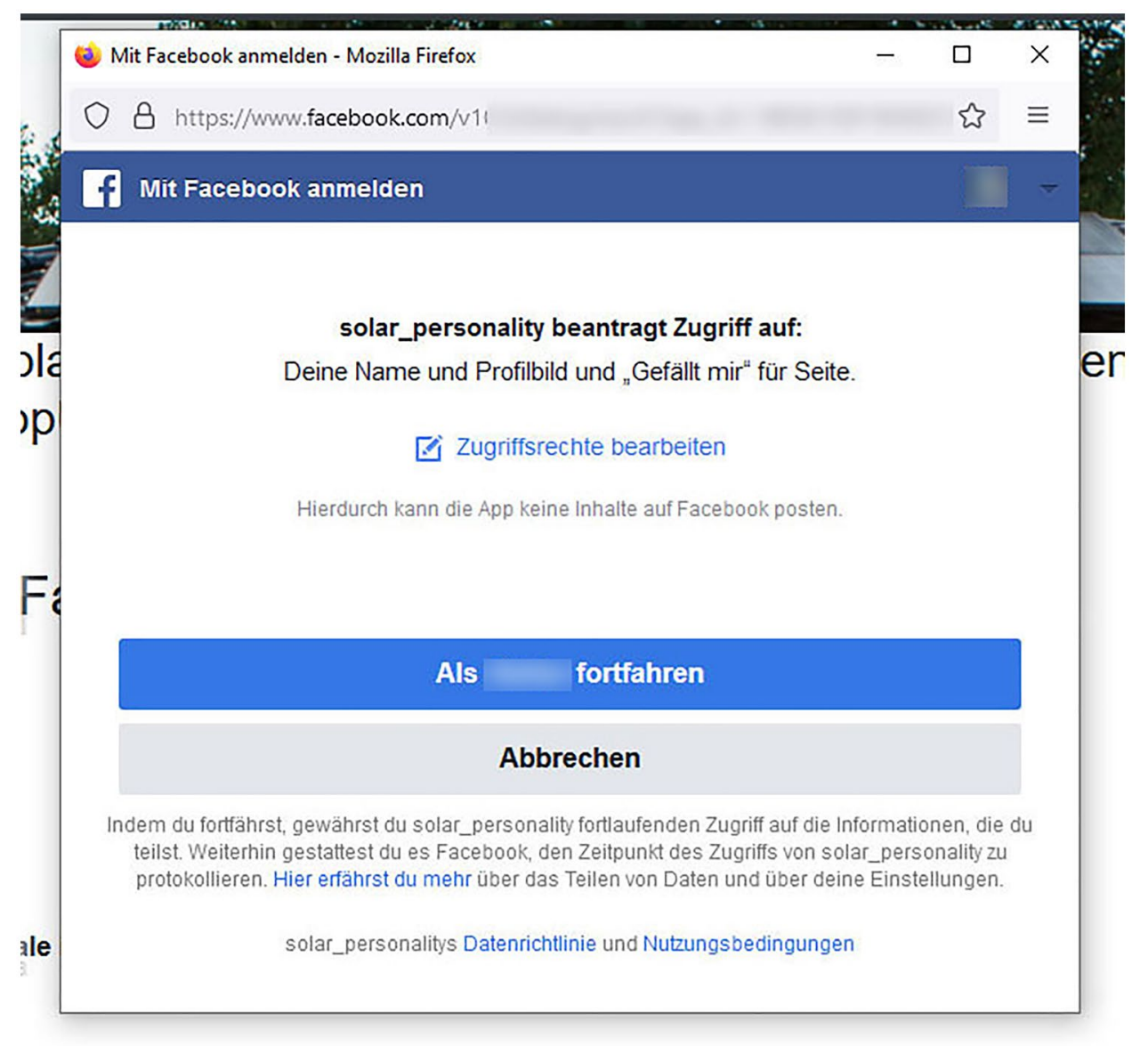


also unclear where the individuals who reacted hostilely to the postings came from since some of them did not belong to the target group. At the end of the questionnaire, the participants could compare their predicted personality profile with their self-assessment using a graphical compilation. This should have created an incentive to provide honest answers in order to receive a reasonable self-assessment. In addition, vouchers for an online department store were raffled among all participants. The ads reached about 55,448 Facebook users but with a manageable level of success. All in all, 3509 individuals visited the starting page of the survey, $213(6.1 \%)$ of whom claimed to own a PV system, which was the basic criterion for participation in the study. Of the 66 cases where participants were able to connect their Facebook account with the app (339 likes, on average), 43 could be used for a prediction because they had enough likes (453 likes, on average).

The German Socio-Economic Panel (SOEP) is a representative, nationwide survey across nearly 15,000 private households (Goebel et al. 2019; Liebig et al. 2019). In this wide-range longitudinal study, more than 25,000 respondents are interviewed year by year. The survey started in 1984, and the most recent data represent wave 35 from 2018 (Liebig et al. 2019). In addition to the questions that are components of every wave of the survey, there are also special topics that flow into the investigation. Among many other topics, the SOEP includes variables about the Big Five personality traits and other psychological items. The data can be retrieved from the German Institute for Economic Research (Deutsches Institut für Wirtschaftsforschung, DIW) at no cost and are reserved exclusively for academic use and for registered researchers. In the years 2005, 2009, 2013, and 2017, a self-completion questionnaire on the Big Five personality traits was part of the SOEP study (DIW Berlin 2007). A short version of the Big Five Inventory was used, called Big Five Inventory Short (BFI-S), with 16 questions. Before the BFI-S was added to the SOEP panel, its external validity was tested and it was considered to be sufficient for capturing users' personality traits (Dehne and Schupp 2007). The internal consistency of the scales was determined by the reliability coefficient Cronbach's alpha $(\alpha)$. Although all values were below the recommended measure of 0.7, Dehne and Schupp argue that the low values are caused by the small number of items and that the mean inter-item correlation of the scales provides good results. Crobach's alpha thus indicates how well the individual items are represented by the scale. The more items are used (the longer the measuring instrument), the better the $\alpha$-values. However, for many participants, the inclination to answer decreases if too many questions are asked. Thus, some researchers note the low reliability of such short scales as in the SOEP or the British Household Panel (Smith et al. 2021). While most studies concerning personality traits investigate student samples, which result in a bias toward young adults with a higher level of education, the great advantage of nationwide studies is their representativeness.

\subsection{Construction of the working sample}

After deletion of all cases where the requirement of a PV system was not answered positively, 159 cases remained. Of these, 16 cases were excluded from the survey because of obviously incorrect answers. Thus, the working sample consists of 143 PV users (mean age 44.3, 18.0\% female), of whom there are 74 owners and 69 non-owners of a battery storage system. Of the 61 participants who managed to connect their Facebook profile to the app, there were 39 who had enough likes for a prediction of personality traits; among them, there were 20 owners and 19 non-owners of a battery storage system. Table 2 gives an overview of the self-assessments.

\subsection{Construction of the control sample}

For comparison, data from the German Socio-Economic Panel (SOEP) were used. In 2015 and 2016, the questionnaire included an item that asked if the household owned a PV system. A total of 13,083 individuals answered this question "yes" or "no." For individuals who took part in both years, only the results of the second administration were left in the dataset (number $(n)=7286,59.7 \%$ male, mean age 56.24). In survey year $2017(n=32,485,51.4 \%$ female, mean age 45.98), a 16-item question battery was used to investigate the Big Five personality traits of the participants. For every trait, a score was calculated when at least one traitrelated question was answered (Table 3 ).

The Big Five scores were added to the PV dataset. The deviation of the total standardized scores from zero could be due to the fact that the majority of participants who answered the question regarding PV ownership were homeowners and were neither very young nor very old people. It is noteworthy, then, that all traits, except for conscientiousness, score below the sample mean of the SOEP study 2017. One reason could be the higher proportion of males and the significantly higher mean age.

\section{Econometric analysis}

For the prediction of personality traits through Facebook likes, a t test with repeated measures was used because the same individuals were assessed first by the AMS app and second through a self-report questionnaire. To evaluate whether battery owners and non-owners could be distinguished, an independent $t$ test was conducted. The independence of the measurements was fulfilled because two different 
Table 2 Big Five personality traits of the 2019 self-reports

\begin{tabular}{llllllll}
\hline & $n$ & Missing & Min & Max & Mean & SD & $\alpha$ \\
\hline Openness & 143 & 0 & 1.00 & 7.00 & 5.035 & 1.243 & .769 \\
Conscientiousness & 143 & 0 & 2.00 & 7.00 & 5.173 & 1.226 & .650 \\
Extraversion & 143 & 0 & 1.00 & 7.00 & 4.455 & 1.305 & .707 \\
Agreeableness & 143 & 0 & 2.33 & 7.00 & 4.888 & 1.022 & .449 \\
Neuroticism & 143 & 0 & 1.00 & 6.67 & 3.578 & 1.286 & .643 \\
Valid N (listwise) & 143 & & & & & &
\end{tabular}

Table 2 presents descriptive statistics of the Big Five personality traits of the 2019 self-reports; $n$, number of cases; $\mathrm{SD}$, standard deviation; $\alpha$, Cronbach's alpha

\begin{tabular}{llllllrl}
\hline & $n$ & Missing & Min & Max & Mean & SD & $\alpha$ \\
\hline Openness & 28,990 & 3495 & 1.00 & 7.00 & 4.969 & 1.082 & .660 \\
Conscientiousness & 29,280 & 3205 & 1.00 & 7.00 & 5.797 & .955 & .614 \\
Extraversion & 29,318 & 3167 & 1.00 & 7.00 & 4.950 & 1.147 & .662 \\
Agreeableness & 29,376 & 3109 & 1.33 & 7.00 & 5.493 & .995 & .508 \\
Neuroticism & 29,402 & 3083 & 1.00 & 7.00 & 3.783 & 1.241 & .588 \\
Valid $N$ (listwise) & 28,628 & & & & & & \\
\hline
\end{tabular}

Table 3 presents descriptive statistics of the Big Five personality traits where all items were completed in the 2017 SOEP study; $n$, number of individuals; SD, standard deviation; $\alpha$, Cronbach's alpha
Table 3 Big Five personality traits in the 2017 SOEP study altered. The $\mathrm{z}$-scores were compared via paired t tests for each Big Five trait. For extraversion $(p=0.081)$ and neuroticism $(p=0.530)$, the null hypothesis of mean level equality could not be rejected, while the correlation was positive only for extraversion $(r=0.318)$ and agreeableness $(r=0.420)$, which is a necessary assumption for predictability (Table 5). Lambiotte and Kosinski (2014) noted that a typical correlation was between $r=0.2$ and $r=0.4$. As an intermediate result, it could be stated that the results of AMS prediction and self-reports were significantly equal and correlated only for extraversion. Or, in other words, the Facebook likes predicted the self-assessments of users to a significance level of $95 \%$ in a sufficient way only for this trait. Figure 2 provides three important comparisons: (1) A comparison between self-assessments from the SOEP study (blue) and all self-assessments from the present investigation (green) revealed the greatest mean deviations in agreeableness and conscientiousness. (2) When all self-assessments from the present investigation (green) and only the self-assessments from individuals whose Facebook profiles could be evaluated (orange) were compared the largest mean deviations were found in openness and extraversion. (3) A comparison of self-assessments of individuals whose Facebook profiles could be evaluated (orange) and their predictions (yellow) showed that users rate themselves as considerably more open and extroverted but less agreeable and conscientious than their Facebook likes predicted. 
Table 4 Statistics of $Z$-scores

\begin{tabular}{|c|c|c|c|c|c|c|c|c|c|c|c|c|}
\hline & \multicolumn{6}{|c|}{ Battery non-adopters } & \multicolumn{6}{|c|}{ Battery adopters } \\
\hline & Mean & $n$ & Median & Min & Max & SD & Mean & $n$ & Median & Min & $\operatorname{Max}$ & SD \\
\hline \multicolumn{13}{|c|}{$z$-scores for predicted percentiles of Big Five traits } \\
\hline Openness & -.16 & 19 & -.11 & -1.03 & .23 & .26 & -.01 & 20 & -.12 & -.61 & 1.49 & .44 \\
\hline Conscientiousness & -.06 & 19 & -.10 & -.51 & .81 & .31 & -.23 & 20 & -.13 & -2.30 & .66 & .54 \\
\hline Extraversion & -.31 & 19 & -.36 & -.56 & .15 & .19 & -.35 & 20 & -.33 & -.82 & .02 & .19 \\
\hline Agreeableness & -.27 & 19 & -.26 & -.80 & .09 & .24 & -.27 & 20 & -.26 & -1.26 & .46 & .33 \\
\hline Neuroticism & -.38 & 19 & -.33 & -1.04 & -.06 & .23 & -.28 & 20 & -.34 & -.61 & .37 & .24 \\
\hline \multicolumn{13}{|c|}{$z$-scores for self-reported scores for Big Five traits } \\
\hline Openness & -.03 & 74 & .03 & -3.67 & 1.88 & 1.16 & .16 & 69 & .26 & -3.67 & 1.88 & 1.14 \\
\hline Conscientiousness & -.78 & 74 & -.66 & -3.98 & 1.26 & 1.34 & -.52 & 69 & -.14 & -3.63 & 1.26 & 1.21 \\
\hline Extraversion & -.51 & 74 & -.25 & -3.15 & 1.79 & 1.09 & -.34 & 69 & -.25 & -3.44 & 1.79 & 1.19 \\
\hline Agreeableness & -.59 & 74 & -.83 & -2.50 & 1.51 & 1.03 & -.63 & 69 & -.83 & -3.17 & 1.51 & 1.03 \\
\hline Neuroticism & -.11 & 74 & -.09 & -2.24 & 2.32 & 1.03 & -.23 & 69 & -.09 & -2.24 & 2.32 & 1.04 \\
\hline
\end{tabular}

Table 4 presents AMS predictions of the Big Five personality traits and self-reported measures converted to $z$-scores; $n$, number of cases; $\mathrm{SD}$, standard deviation

Table 5 Mean level comparison of self-reports and predictions

\begin{tabular}{|c|c|c|c|c|c|c|c|c|}
\hline & \multicolumn{6}{|c|}{ Paired differences } & \multicolumn{2}{|c|}{ Correlations } \\
\hline & Mean & SD & Std. Error Mean & $t$ & $d f$ & $p$ & $r$ & $p(r)$ \\
\hline Openness & -.649 & .847 & .136 & -4.789 & 38 & .000 & -.055 & .738 \\
\hline Conscientiousness & .487 & 1.326 & .212 & 2.292 & 38 & .028 & -.121 & .464 \\
\hline Extraversion & -.284 & .992 & .159 & -1.790 & 38 & .081 & .318 & .048 \\
\hline Agreeableness & .344 & .987 & .158 & 2.179 & 38 & .036 & .420 & .008 \\
\hline Neuroticism & -.119 & 1.169 & .187 & -.633 & 38 & .530 & -.029 & .861 \\
\hline
\end{tabular}

Reported are paired $t$ tests $(n=39)$ for Big Five personality traits for PV owners (prediction-self-reports). $\mathrm{SD}$, standard deviation; $t$, value of $t$ test; $d f$, degrees of freedom; $p, p$-value; $r$, Pearson's correlation; $p(r)$, $p$-value of correlation

\subsection{Distinguishability between user groups}

Following the comparison of self-assessment and prediction, whether owners and non-owners of batteries differ significantly should be investigated. For this purpose, a t test for independent samples should be conducted in the first step, which tested the group mean values of predicted scores for differences. None of the p-values was significant, and thus, the null hypothesis of equality of means cannot be rejected (Table 6). As a result, it can be assumed that the groups cannot be distinguished by their mean values. In order to verify whether the failed distinctness affected only the predicted values, the self-reported scores were also checked. A second $t$ test was conducted, and again, the $p$-values revealed no significant differences between the two groups. Owners and non-owners of batteries could not be distinguished either by the AMS predictions or the self-assessments of the Big Five personality traits. Thus, the Big Five alone were clearly not suitable for determining group membership.

A linear discriminant analysis (LDA) should show whether the Big Five personality traits have a discriminant property on the two user groups and whether an enrichment with further variables can enable differentiation. This proceeding originates from the finance and insurance industry, where it is used to assess whether a consumer is creditworthy or not, depending on several predictor variables. The discriminant analysis was first conducted with only the predicted Big Five traits; in a second step, demographic variables were added; and in a third step, risk preferences and risk perceptions completed the set of independent variables. The first analysis gave an eigenvalue of only 0.090 with a canonical correlation of 0.288 and Wilks' lambda of $0.917(p=0.703)$. Thus, the whole model was not significant. Neuroticism and openness could be determinants of battery ownership, and conscientiousness, extraversion, and agreeableness were possible predictors of non-ownership. The model was able to classify $51.3 \%$ of the cases correctly, which was marginally more than chance. When demographic variables like age, gender, education, and family status were added, the eigenvalue increased to 0.256 with a correlation of 0.452 . Wilks' lambda is $0.796(p=0.642)$. The model could 
Fig. 2 Self-assessments and predictions compared to SOEP data. Note: Figure presents mean scores of the Big Five personality trait z-scores for photovoltaic adopters from the SOEP study $(n=425$, blue), all self-reports from the present study ( $n=139$, green), self-reports from the present study with predictions $(n=39$, orange), predictions from AMS ( $n=39$, yellow); $n=$ number of individuals

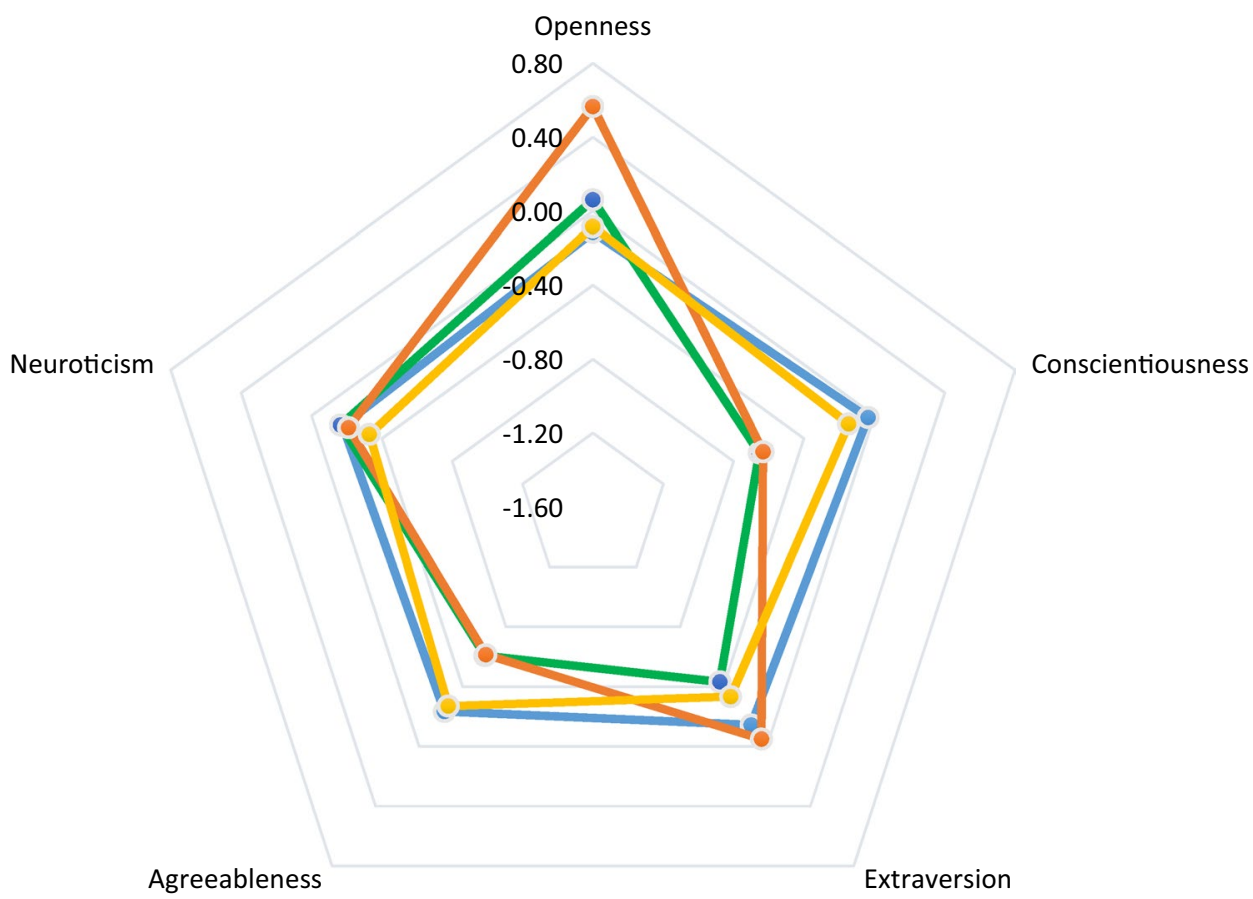

$\begin{array}{ll}- \text { Solar users 2016, based on SOEP } 2017 & \text { Self-reports total }(\mathrm{n}=139) \\ & =\text { Self-reports }(\mathrm{n}=39)\end{array}$

Table 6 Mean levels of battery adopters and non-adopters

\begin{tabular}{|c|c|c|c|c|c|c|c|}
\hline & \multicolumn{4}{|c|}{ Levene statistic } & \multicolumn{3}{|c|}{$t$ test for Equality of Means } \\
\hline & $n$ & $F$ & Sig & $t$ & Mean difference & $\begin{array}{l}\text { Std. error } \\
\text { difference }\end{array}$ & $p$ \\
\hline \multicolumn{8}{|l|}{ AMS predictions } \\
\hline Openness & 39 & 1.894 & .177 & -1.299 & -.151 & .116 & .202 \\
\hline Conscientiousness & 39 & .171 & .681 & 1.161 & .164 & .141 & .253 \\
\hline Extraversion & 39 & .102 & .751 & .685 & .042 & .061 & .497 \\
\hline Agreeableness & 39 & .149 & .701 & .010 & .000 & .092 & .992 \\
\hline Neuroticism & 39 & .413 & .524 & -1.421 & -.107 & .076 & .164 \\
\hline \multicolumn{8}{|l|}{ Self-assessments } \\
\hline Openness & 143 & .002 & .966 & -.988 & -.189 & .191 & .325 \\
\hline Conscientiousness & 143 & 1.314 & .254 & -1.245 & -.266 & .213 & .215 \\
\hline Extraversion & 143 & .591 & .443 & -.893 & -.170 & .190 & .373 \\
\hline Agreeableness & 143 & .190 & .664 & .263 & .045 & .172 & .793 \\
\hline Neuroticism & 143 & .167 & .683 & .678 & .178 & .174 & .499 \\
\hline
\end{tabular}

Reported are independent $t$ tests for Big Five personality trait predictions $(n=39)$ and self-assessments $(n=143)$ for both battery adopters and non-adopters

$n$, number of individuals; $F, F$-value (Levene test); Sig., $p$-value for Levene test; $t, t$-statistic; $p, p$-value classify $67.5 \%$ correctly but was still not significant. When the number of persons in the household and the household income and expenses were added, the model could classify $73.0 \%$ correctly but was still insignificant. When risk propensity and risk perceptions in several domains were added, the eigenvalue increased to 2.787 with a correlation of 0.858 and Wilks' lambda is $0.264(p=0.022)$. Neuroticism and openness were still determinants of battery ownership. The model was able to classify $91.4 \%$ of the cases correctly. As a result, the Big Five personality traits contributed only to a small degree to the differentiation between the user groups. Instead of using latent variables 
as predictor variables, i.e., Big Five personality traits, the like-IDs of the Facebook pages could be used as a source for the discriminant analysis. A user-like matrix was created from a total of 19,335 different pages related to 61 individuals (mean number of likes $=335, \mathrm{SD}=542.4$, $\min =2, \max =3495$ ), 29 of whom were battery owners and 32 were not. Every time an individual liked a single page, this was represented by 1 or otherwise by 0 . Both were equally weighted. To reduce complexity, the matrix was trimmed to all cases with at least 20 liked pages per user and at least 2 users per page (see also Kosinski et al. (2016)). The result was a matrix consisting of 1846 pages by 43 users ( 4 users had to be deleted because of incorrect answers) with 79,378 cells. Although discriminant analysis actually requires continuous variables, it can also be conducted with $1 / 0$ coded binary independent variables. According to the central limit theorem, a normal distribution of the independent variables could be assumed for a sample larger than 30. A step-wise LDA was conducted to explore the contribution of the likes to the ownership of a solar battery. Since ultimately only 16 variables were included in the equation, the condition that more cases should be considered as parameters was also fulfilled. For both user groups, it was striking that, among the top 20 most-liked pages, for battery owners and non-owners, 5 and 9, respectively, were for comedy or satirical entertainment. The most popular fan page for PV owners was "Der Postillon," a satirical news website. Pages with the most discriminant properties are listed in Table 7. The most important page for non-owners was "DFB Frauen," a fan page for the German women's soccer association. The page with the highest selectivity for owners was "Sonnen Batterie," a manufacturer of solar batteries.

The Facebook likes could classify $100.0 \%$ of all 43 cases correctly with an eigenvalue of the model of 2,178.473 (canonical correlation $r=1.000$ ) and a Wilks' lambda of $0.000(p=0.000)$. Even the cross-validated result revealed a 93\% correct classification. Thus, LDA was suitable to predict the correct group of PV owners, according to the present data. In contrast, it was not possible to derive a prediction from the Big Five personality traits alone, nor could the Big Five be determined by single likes.

The results of the discriminant analysis could not be substantiated by a logistic regression. For a total of 61 users29 owners and 32 non-owners of a storage battery-19,335 different pages were regressed on the dependent variable, and none of them provided even the slightest significant results.

\section{Discussion}

The $t$ tests revealed that the means of the Big Five z-scores were only predicted sufficiently for neuroticism and extraversion. Extraversion and agreeableness had significant positive Pearson's correlations between self-assessments and predictions. Thus, only extraversion was sufficiently correctly predicted by the Apply Magic Sauce API for all
Table 7 Discriminant coefficients of facebook likes

\begin{tabular}{llrl}
\hline Like-ID & Name & SCDFC & Category \\
\hline Battery owners $(n=20)$ & & & \\
188688131822001 & Sonnen Batterie & 31.55 & Solar Battery Manufacturer \\
31649251356 & CSI Miami & 25.94 & TV Series \\
129773947075202 & Pitztaler Gletscher & 24.15 & Pitztal Glacierski area \\
1453306071441090 & \#\#\# private \#\#\# & 24.15 & \\
202102663791918 & Aufstehen & 23.05 & Leftwing political Organization \\
166200743435821 & ODP Bayern & 21.33 & Oecological Political Party \\
26101560328 & Depeche Mode & 19.29 & Music Group, Band \\
111938328822261 & Das A-Team & 13.96 & TV-Series \\
553944091603407 & Energiewende-Rocken & 3.74 & Energy Transition Activism \\
1454797278158590 & \#\#\# private \#\#\# & 2.42 & \\
513607188730244 & Harry Gueber & 2.12 & Regional Comedian \\
Battery non-owners $(n=23)$ & & \\
102362899824580 & DFB-Frauen & -8.16 & German Women's Soccer \\
118598124966673 & Katharina Schulze & -6.61 & Political MPs (Green Party) \\
69755621604 & Monaco Franze & -5.70 & Fictional TV-Series Character \\
204139474516 & abgeordnetenwatch.de & -3.26 & Political activism \\
108110462544365 & Fußball & -.76 & About Football \\
\hline
\end{tabular}

Table 8 presents standardized canonical discriminant function coefficients (SCDFC) from a step-wise linear discriminant analysis of Facebook likes for battery owners and non-owners 
photovoltaic users. Although the alpha reliability of the traits measured was generally low, it was in the acceptable range for extraversion at 0.707 . In the data of the SOEP study, good measurement characteristics could be demonstrated for extraversion for the same scale (Smith et al. 2021). The mean deviation for agreeableness with simultaneous positive correlation could indicate, on the one hand, that the predictions do not apply. On the other hand, it could also indicate that Facebook users regularly rate their own agreeableness lower than is actually the case (Table 5). This question should be investigated further. The results for extraversion and conscientiousness support the findings of Marengo et al. (2020). Among other things, they found that the self-assessments of users versus non-users of Facebook did not differ for conscientiousness, while there were significant differences for extraversion. Although extraversion could be predicted correctly by the Facebook likes, the hypothesis that the Big Five personality traits are significantly different between adopters and non-adopters of electricity storage systems failed. Between the two groups, significant differences could not be found for the self-assessments or the predictions (Table 6). Further, it was not possible to distinguish between battery adopters and non-adopters because the variances overlap in large parts for all Big Five traits. This can also be seen in Table 4, where the standard deviations of the users' self-reports are up to five times higher than the standard deviations of the AMS predictions. The most likely cause for this may be the rather small sample size, as this leads to strongly varying standard deviations. Apart from personality traits, however, there was a possibility to use the digital footprint in the form of the liked pages to differentiate between user groups. A sole consideration of the Big Five enabled a prediction of group membership, which was not much higher than chance. The additional inclusion of demographic characteristics increased the proportion of correct classifications to $93.8 \%$. Regarding the usefulness of Facebook likes as a distinguishing characteristic between adopters and non-adopters, a linear discriminant analysis uncovered 16 pages that determined adopters and non-adopters of battery storage. One could say that if you are an owner of a PV system and you like CSI: Miami, then you are likely to own a battery system, and if you like football-especially the German women's team-it is likely that you do not. However, the single likes could not be clearly assigned to the Big Five.

There exist, of course, several other limitations. The applicability of linear discriminant analysis should be tested with a much larger sample. Although the normality assumption is fulfilled according to the central limit theorem, the suggestions of Feldesman (2002) could be taken up. He recommends classification trees as a non-parametric tool for classifying user groups when the assumptions for LDA are not met.

The database of the Apply Magic Sauce API is from 2012. This means Facebook pages created later could not be used to estimate the Big Five personality traits. Furthermore, the API users come from all around the world, mostly from the US, with a large proportion of younger people. While this does not necessarily mean the predictions are not correct for German users, the pages that are suitable for a prediction relate mostly to the interests of American users. This results in a lower share of possible predictions among users of the AMS-API outside the US.

The sample's personality traits are biased toward higher scores of openness and higher extraversion and lower values of conscientiousness and agreeableness. This is likely because only individuals who are very open-minded toward new technologies and experiences are (a) members of a social network and (b) willing to take part in a survey that analyzes their personality, while in Europe at that time, everyone was talking about data protection issues and the danger associated with using American online services.

More research with larger sample sizes is needed to draw conclusions from the users' digital footprints, e.g., liked pages, to self-report Big Five scores and, thus, to build a study's own database or to prove whether there is really no significant difference between the personality traits of battery adopters and non-adopters. Unfortunately, increased consumer awareness of data protection issues has severely limited the acceptance of empirical research in the online sector. Furthermore, hardly any company would risk making personal user data available for scientific purposes.

\section{Conclusions}

This research aimed to investigate whether the Facebook likes of owners of PV systems were suitable for assessing whether they own an electricity storage system. Althoughaccording to Youyou et al. (2015) — analysis of the digital footprint is well-suited to making a prediction about the Big Five personality traits, a satisfactory prediction about the mean value could be found only for extraversion. Agreeableness showed a positive correlation, but predictions differed from self-assessments. The second hypothesis, that significant differences exist between adopters and non-adopters of battery storage, could not be confirmed.

Although the results did not correspond to the hypotheses, this study provides suggestions for further research in this area. Reliable results require, above all, larger samples and comparable data without having to take a detour via $\mathrm{z}$-scores. For example, a suitable data source is the German core energy market data register (Marktstammdatenregister), which stores all solar power generators 
in Germany. However, the European general data protection regulation (GDPR) sets high hurdles for the usability of the data for scientific studies, especially in connection with social network analysis. Additionally, further research should be based on detailed scales rather than ultra-short scales. This would also allow an in-depth investigation using structural equation modeling.

Table 8 Used facebook groups and member count

\begin{tabular}{ll}
\hline Group name & $\begin{array}{l}\text { Number of } \\
\text { group mem- } \\
\text { bers }\end{array}$ \\
\hline Photovoltaik & 6522 \\
sonnenBatterie-Besitzer & 703 \\
EUROPÄISCHE ENERGIEWENDE & 12,202 \\
E3/DC Speicherfreunde S10 Etc & 1073 \\
Photovoltaik/Solarforum—Info—Service und Verkauf & 513 \\
Photovoltaik und Stromspeicher & 210 \\
Dezentrale Energiewende & 319 \\
Das Netzwerk der Energiewende & 1852 \\
Photovoltaik-Gruppe & 305 \\
SolarPeople-Ein Forum für Solarenergie & 55 \\
Photovoltaik Fotovoltaik Windkraft Windkraftanlagen & 1549 \\
BHKW Biogas Biomasse & 97 \\
Solarenergie-Fragen und Antworten ! & 1166 \\
Grüne Ökonomie: nachhaltiges Wirtschaften und & \\
erneuerbare Energie & 26,566 \\
Total &
\end{tabular}

\section{Appendix}

See Tables 8, 9, 10, 11, 12, and 13.

\section{Appendix 2: Questionnaire}

\section{Page 1}

Q01 Do you own a solar power generation system (photovoltaic)?

- yes

- no

\section{Page 2}

Q02 Who in your household had the idea to purchase a PV system?

- Myself

- My partner

- Both together

- Someone else

Q03 What is the approximate power of your PV system (in $\mathrm{kWp})$ ? [please select]
Table 9 Statistics of the Big Five, original measures

\begin{tabular}{|c|c|c|c|c|c|c|c|c|c|c|c|c|}
\hline & \multicolumn{6}{|c|}{ Battery non-owners } & \multicolumn{6}{|c|}{ Battery owners } \\
\hline & Mean & $N$ & Median & Min & Max & SD & Mean & $N$ & Median & Min & Max & SD \\
\hline \multicolumn{13}{|c|}{ Predicted percentiles of Big Five traits } \\
\hline $\mathrm{O}$ & .440 & 19 & .456 & .153 & .593 & .092 & .488 & 20 & .453 & .271 & .932 & .144 \\
\hline $\mathrm{C}$ & .475 & 19 & .461 & .305 & .790 & .115 & .431 & 20 & .447 & .011 & .744 & .131 \\
\hline $\mathrm{E}$ & .379 & 19 & .359 & .288 & .559 & .073 & .364 & 20 & .370 & .207 & .510 & .068 \\
\hline A & .397 & 19 & .398 & .211 & .534 & .087 & .399 & 20 & .397 & .105 & 679 & .113 \\
\hline $\mathrm{N}$ & .355 & 19 & .372 & .149 & .476 & .076 & .393 & 20 & .367 & .273 & .645 & .094 \\
\hline \multicolumn{13}{|c|}{ Self-reported original raw scores for Big Five traits } \\
\hline $\mathrm{O}$ & 4.94 & 74 & 5.00 & 1.00 & 7.00 & 1.26 & 5.14 & 69 & 5.25 & 1.00 & 7.00 & 1.23 \\
\hline $\mathrm{C}$ & 5.05 & 74 & 5.17 & 2.00 & 7.00 & 1.28 & 5.30 & 69 & 5.67 & 2.33 & 7.00 & 1.16 \\
\hline $\mathrm{E}$ & 4.36 & 74 & 4.67 & 1.33 & 7.00 & 1.25 & 4.56 & 69 & 4.67 & 1.00 & 7.00 & 1.36 \\
\hline A & 4.91 & 74 & 4.67 & 3.00 & 7.00 & 1.02 & 4.86 & 69 & 4.67 & 2.33 & 7.00 & 1.03 \\
\hline $\mathrm{N}$ & 3.65 & 74 & 3.67 & 1.00 & 6.67 & 1.28 & 3.50 & 69 & 3.67 & 1.00 & 6.67 & 1.30 \\
\hline
\end{tabular}

Table presents AMS predictions of the Big Five personality traits as percentiles, self-reported measures as raw scores

O, Openness; C, Conscientiousness; E, Extraversion; A, Agreeableness; N, Neuroticism; SD, standard deviation; $\alpha$, Cronbach's alpha 
Table 10 Big Five personality traits in detail. Source: McCrae and Costa (1999)

\begin{tabular}{ll}
\hline Personality traits & Personality trait facets
\end{tabular}

Openness to experience: the active seeking and appreciation of experi- Fantasy: receptivity to the inner world of imagination

ences for their own sake

Conscientiousness: degree of organization, persistence, control, and motivation in goal-directed behavior

Extraversion: quantity and intensity of energy directed outward into the social world

Agreeableness: the kinds of interactions an individual prefers, from compassion to tough mindedness

Neuroticism: identifies individuals who are prone to psychological distress
Aesthetics: appreciation of art and beauty

Feelings: openness to inner feelings and emotions

Actions: openness to new experiences on a practical level

Ideas: intellectual curiosity

Values: readiness to re-examine own values and those of authority figures

Competence: belief in own self-efficacy

Order: personal organization

Dutifulness: emphasis placed on importance of fulfilling moral obligations

Achievement Striving: need for personal achievement and sense of direction

Self-Discipline: capacity to begin tasks and follow through to completion despite boredom or distractions

Deliberation: tendency to think things through before acting or speaking

Warmth: interest in and friendliness toward others

Gregariousness: preference for the company of others

Assertiveness: social ascendancy and forcefulness of expression

Activity: pace of living

Excitement Seeking: need for environmental stimulation

Positive Emotions: tendency to experience positive emotions

Trust: belief in the sincerity and good intentions of others

Straightforwardness: frankness in expression

Altruism: active concern for the welfare of others

Compliance: response to interpersonal conflict

Modesty: tendency to play down own achievements and be humble

Tender-Mindedness: attitude of sympathy for others

Anxiety: level of free-floating anxiety

Angry Hostility: tendency to experience anger and related states such as frustration and bitterness

Depression: tendency to experience feelings of guilt, sadness, despondency, and loneliness

Self-Consciousness: shyness or social anxiety

Impulsiveness: tendency to act on cravings and urges rather than reining them in and delaying gratification

Vulnerability: general susceptibility to stress
- under $1 \mathrm{kWp}$

- 1 -under $2 \mathrm{kWp}$

- 2 -under $3 \mathrm{kWp}$

- 3-under $4 \mathrm{kWp}$

- 4-under $5 \mathrm{kWp}$

- 5-under $6 \mathrm{kWp}$

- 6-under $7 \mathrm{kWp}$

- 7 -under $8 \mathrm{kWp}$

- 8-under $9 \mathrm{kWp}$

- 9-under $10 \mathrm{kWp}$

- more than $10 \mathrm{kWp}$

Q04 In which year was your PV system installed? [Please select]
Q05 How expensive was your PV system approximately (incl. VAT)? [Please select]

- less than 2500 Euro

- 2500-under 4000 Euro

- 4000-under 6000 Euro

- 6000-under 8000 Euro

- 8000-under 10,000 Euro

- 10,000-under 12,000 euros

- 12,000-under 14,000 Euro

- 14,000-under 16,000 Euro

- 16,000-under 18,000 Euro

- 18,000-under 20,000 Euro

- more than 20,000 Euro 
Table 11 Descriptive statistics of present study

\begin{tabular}{|c|c|c|c|c|c|c|c|c|c|}
\hline & \multicolumn{3}{|c|}{ Adopters } & \multicolumn{3}{|c|}{ Non-Adopters } & \multicolumn{3}{|l|}{ Total } \\
\hline & $N$ & Mean/\% & $\mathrm{SD}^{\mathrm{a}}$ & $N$ & Mean/\% & $\mathrm{SD}^{\mathrm{a}}$ & Valid & Mean/\% & $\mathrm{SD}^{\mathrm{a}}$ \\
\hline Age of participant & 60 & 43.53 & 15.03 & 67 & 45.00 & 18.72 & 127 & 44.31 & 17.02 \\
\hline \multicolumn{10}{|l|}{ Monthly income of the household in Euro } \\
\hline $0=$ Less than 250 & 0 & 0 & & 0 & 0 & & 0 & 0 & \\
\hline $1=250-499$ & 0 & 0 & & 2 & 2.7 & & 2 & 1.4 & \\
\hline $2=500-999$ & 1 & 1.4 & & 2 & 2.7 & & 3 & 2.1 & \\
\hline $3=1000-1499$ & 1 & 1.4 & & 4 & 5.4 & & 5 & 3.5 & \\
\hline $4=1500-1999$ & 2 & 2.9 & & 7 & 9.5 & & 9 & 6.3 & \\
\hline $5=2000-2999$ & 6 & 8.7 & & 12 & 16.2 & & 18 & 12.6 & \\
\hline $6=3000-3999$ & 14 & 20.3 & & 13 & 17.6 & & 27 & 18.9 & \\
\hline $7=4000-4999$ & 7 & 10.1 & & 11 & 14.9 & & 18 & 12.6 & \\
\hline $8=$ More than & 25 & 36.2 & & 12 & 16.2 & & 37 & 25.9 & \\
\hline 5000 missing & 6 & 8.7 & & 8 & 10.8 & & 14 & 9.8 & \\
\hline Number of individuals in the household & 62 & 3.13 & 1.41 & 71 & 3.08 & 1.28 & 133 & 3.11 & 1.34 \\
\hline Gender & 69 & 100 & & 74 & 100 & & 133 & 100 & \\
\hline $0=$ male & 52 & 75.4 & & 54 & 73 & & 106 & 74.1 & \\
\hline $1=$ female & 9 & 13 & & 15 & 20.3 & & 24 & 16.8 & \\
\hline $2=$ diverse & 1 & 1.4 & & 2 & 2.7 & & 3 & 2.1 & \\
\hline Missing & 7 & 10.1 & & 3 & 4.1 & & 10 & 7 & \\
\hline \multicolumn{10}{|l|}{ Marital status } \\
\hline single & 7 & 10.1 & & 5 & 6.8 & & 12 & 8.4 & \\
\hline with partner & 22 & 31.9 & & 27 & 36.5 & & 49 & 34.3 & \\
\hline married & 32 & 46.4 & & 39 & 52.7 & & 71 & 49.7 & \\
\hline divorced & 1 & 1.4 & & 0 & 0 & & 1 & .7 & \\
\hline missing & 7 & 10.1 & & 3 & 4.1 & & 10 & 7 & \\
\hline \multicolumn{10}{|l|}{ Level of education } \\
\hline $0=$ no degree & 2 & 2.9 & & 1 & 1.4 & & 3 & 2.1 & \\
\hline \multicolumn{10}{|l|}{$2=$ lower-secondary education } \\
\hline \multicolumn{10}{|l|}{$5=$ upper-secondary education } \\
\hline \multirow[t]{4}{*}{$7=$ other missing } & 17 & 24.6 & & 19 & 26.8 & & 36 & 25.2 & \\
\hline & 42 & 60.9 & & 51 & 71.8 & & 93 & 65 & \\
\hline & 1 & 1.4 & & 0 & 0 & & 1 & .7 & \\
\hline & 7 & 10.1 & & 3 & 4.1 & & 10 & 7 & \\
\hline \multicolumn{10}{|l|}{ Vocational education } \\
\hline $0=$ unskilled & 2 & 2.9 & & 8 & 10.8 & & 10 & 7 & \\
\hline worker & 25 & 36.2 & & 22 & 29.7 & & 47 & 32.9 & \\
\hline $2=$ professional skills & 30 & 43.5 & & 40 & 54.1 & & 70 & & \\
\hline & 49 & & & & & & & & \\
\hline $5=$ technician, college, university degree & 2 & 2.9 & & 0 & 0 & & 2 & 1.4 & \\
\hline $11=$ other missing & 10 & 14.4 & & 4 & 5.5 & & 14 & 9.8 & \\
\hline
\end{tabular}

Table shows descriptive statistics $(n=143)$

Q06 What was the total generation of your PV system in the last 12 months approximately (in $\mathrm{kWh}$ )? [Please select]

- under $2500 \mathrm{kWh}$

- 2500-under $4000 \mathrm{kWh}$

- 4000-under $5000 \mathrm{kWh}$

- 5000-under $6000 \mathrm{kWh}$
- 6000 —under $7000 \mathrm{kWh}$

- 7000 - under $8000 \mathrm{kWh}$

- 8000-under 10,000 kWh

- 10,000 - under $12,000 \mathrm{kWh}$

- 12,000 - under $14,000 \mathrm{kWh}$

- 14,000-under 20,000 kWh

- more than $20,000 \mathrm{kWh}$ 
Table 12 Descriptive statistics of control group from SOEP study

\begin{tabular}{|c|c|c|c|c|c|c|c|c|c|}
\hline & \multicolumn{3}{|c|}{ PV owners } & \multicolumn{3}{|c|}{ PV non-owners } & \multicolumn{3}{|l|}{ Total } \\
\hline & $N$ & Mean/\% & $\mathrm{SD}^{\mathrm{a}}$ & $N$ & Mean/\% & $\mathrm{SD}^{\mathrm{a}}$ & Valid & Mean/\% & $\mathrm{SD}^{\mathrm{a}}$ \\
\hline Age of participant & 517 & 53.75 & 12.53 & 6769 & 56.43 & 15.11 & 7286 & 56.24 & 14.96 \\
\hline \multicolumn{10}{|c|}{ Monthly income of the household in Euro } \\
\hline $0=$ Less than 250 & 0 & 0 & & 2 & 0 & & 2 & 0 & \\
\hline $1=250-499$ & 2 & 0.4 & & 20 & 0.3 & & 22 & 0.3 & \\
\hline $2=500-999$ & 2 & 0.4 & & 122 & 1.8 & & 124 & 1.7 & \\
\hline $3=1000-1499$ & 16 & 3.1 & & 418 & 6.2 & & 434 & 6 & \\
\hline $4=1500-1999$ & 16 & 3.1 & & 590 & 8.7 & & 606 & 14.3 & \\
\hline $5=2000-2999$ & 97 & 18.8 & & 1532 & 22.6 & & 1629 & 22.4 & \\
\hline $6=3000-3999$ & 113 & 21.9 & & 1470 & 21.7 & & 1583 & 21.7 & \\
\hline $7=4000-4999$ & 95 & 18.4 & & 949 & 14 & & 1044 & 14.3 & \\
\hline $8=$ More than & 151 & 29.2 & & 1264 & 18.7 & & 1415 & 19.4 & \\
\hline 5000 Missing & 25 & 4.8 & & 402 & 6 & & 427 & 5.9 & \\
\hline Average & 517 & 3938 & 2007 & 6769 & 3393 & 2346 & 7286 & 3432 & 2327 \\
\hline Gender & 517 & 100 & & 6769 & 100 & & 7286 & 100 & \\
\hline $1=$ male & 334 & 64.6 & & 4014 & 59.3 & & 4348 & 59.7 & \\
\hline $2=$ female & 183 & 35.4 & & 2755 & 40.7 & & 2938 & 40.3 & \\
\hline \multicolumn{10}{|l|}{ Marital status } \\
\hline Single & 41 & 7.9 & & 1230 & 18.2 & & 1271 & 17.4 & \\
\hline With partner & 0 & 0 & & 0 & 0 & & 0 & 0 & \\
\hline Married & 449 & 86.8 & & 4918 & 72.7 & & 5367 & 73.7 & \\
\hline Divorced & 26 & 5.0 & & 592 & 8.7 & & 618 & 8.5 & \\
\hline missing & 1 & .2 & & 29 & .4 & & 30 & .4 & \\
\hline \multicolumn{10}{|l|}{ Level of school education } \\
\hline $0=$ no degree & 1 & .2 & & 44 & .7 & & 43 & 6 & \\
\hline $2=$ lower secondary education & 32 & 6.2 & & 481 & 7.1 & & 513 & 7.0 & \\
\hline $3=$ upper secondary education & 202 & 39.1 & & & 3053 & 45.1 & & 3255 & 44.7 \\
\hline $4=$ post-secondary education & 91 & 17.6 & & 996 & 14.7 & & 1087 & 14.9 & \\
\hline $6=$ Bachelor & 120 & 23.2 & & 1337 & 19.8 & & 1457 & 20 & \\
\hline $7=$ Master & 63 & 12.2 & & 738 & 10.9 & & 801 & 11 & \\
\hline $8=$ Doctorate degree & 6 & 1.2 & & 78 & 1.2 & & 84 & 1.2 & \\
\hline Missing & 2 & .4 & & 44 & .7 & & 46 & .6 & \\
\hline
\end{tabular}

Table shows descriptive statistics of the SOEP study 2015-2017 $(n=7286)$

Q07 Approximately how many kWh of this have you fed into the grid in the last 12 months? [Please select]

- less than $2500 \mathrm{kWh}$

- 2500-under $4000 \mathrm{kWh}$

- 4000-under $5000 \mathrm{kWh}$

- 5000-under $6000 \mathrm{kWh}$

- 6000-under $7000 \mathrm{kWh}$

- 7000-under $8000 \mathrm{kWh}$

- 8000-under 10,000 kWh

- 10,000 - under $12,000 \mathrm{kWh}$

- 12,000 - under $14,000 \mathrm{kWh}$

- 14,000-under $20,000 \mathrm{kWh}$

- more than $20,000 \mathrm{kWh}$
Q08 How high is your feed-in tariff approximately (in ct/ $\mathrm{kWh})$ ?

Q09 Do you own a solar power storage system (battery)?

- yes

- not yet, but I am seriously thinking about it

- I have considered it, but discarded it

- No 
Table 13 Top 15 fan pages of PV users

\begin{tabular}{|c|c|c|c|c|c|c|c|}
\hline \multirow[b]{2}{*}{ Rank } & \multicolumn{3}{|l|}{ Battery owners } & \multirow[b]{2}{*}{ Rank } & \multicolumn{3}{|l|}{ Battery non-owners } \\
\hline & Name & Like-ID & $n$ & & Name & Like-ID & $n$ \\
\hline 1 & Postillon & 268611646525 & 14 & 1 & Heute Show & 264820405985 & 12 \\
\hline 2 & Extra 3 & 37621248917 & 8 & 1 & Postillon & 268611646525 & 12 \\
\hline 2 & Sonnen.de & 188688131822001 & 8 & 2 & Extra 3 & 37621248917 & 11 \\
\hline 3 & Campact & 82734241364 & 5 & 3 & ruthe.de & 289955244416 & 8 \\
\hline 3 & Quer & 103687920727 & 5 & 3 & Tagesschau & 193081554406 & 8 \\
\hline 3 & Helge Schneider & 149234265133802 & 5 & 4 & Amazon.de & 141727802539968 & 7 \\
\hline 3 & Tatortreiniger & 174071539353019 & 5 & 5 & Jan Boehmermann & 110495738982958 & 6 \\
\hline 3 & Pfusch am Bau & 268646656590270 & 5 & 5 & Zeit online & 37816894428 & 6 \\
\hline 4 & ZDF heute-show & 264820405985 & 4 & 5 & Campact & 82734241364 & 6 \\
\hline 4 & Senator Sanders & 9124187907 & 4 & 6 & Dieter Nuhr & 113781618677139 & 5 \\
\hline 4 & National Geographic & 23497828950 & 4 & 6 & LAD Bible & 199098633470668 & 5 \\
\hline 4 & CSIMiami & 31649251356 & 4 & 6 & \#\#\# private \#\#\# & 1669506439965710 & 5 \\
\hline 4 & Tatort & 33214866692 & 4 & 7 & Dr. House & 7608631709 & 4 \\
\hline 4 & Der Spiegel & 38246844868 & 4 & 7 & How I Met Your Mother & 7807422276 & 4 \\
\hline 4 & Sportfreunde Stiller & 55085570811 & 4 & 7 & The Big Bang Theory & 2293468477 & 4 \\
\hline 4 & Amazon.de & 141727802539968 & 4 & 7 & Der Spiegel & 38844868 & 4 \\
\hline 4 & Miniatur Wunderland & 71726614987 & 4 & 7 & quer & 103687920727 & 4 \\
\hline 4 & Süddeutsche Zeitung & 215982125159841 & 4 & 7 & Miniatur Wunderland & 71726614987 & 4 \\
\hline 4 & ZDF heute & 112784955679 & 4 & 7 & Unnützes Wissen & 97848298204 & 4 \\
\hline \multirow[t]{3}{*}{4} & Bob Marley & 117533210756 & 4 & 7 & Joscha Sauer & 131582549993 & 4 \\
\hline & & & & 10 & DFB-Frauen & 102362899824580 & 1 \\
\hline & & & & 10 & Katharina Schulze & 118598124966673 & 1 \\
\hline
\end{tabular}

Table presents the top 20 Facebook fan pages of battery owners and non-adopters. Most-discriminant pages (at least 20 pages per user, 2 users per page) are highlighted in bold

\section{Page 3-Personality Traits}

Q10 Here are different characteristics that a person can have. Probably some characteristics will fully apply to you personally and others not at all. For still others, you may be undecided

Please answer using the following scale. A value of 1 means: not at all true.

The value 7 means: fully applies. You can use the values between 1 and 7 to grade your opinion.

I am someone who ...

1) works thoroughly

2) is communicative, talkative

3 ) is sometimes a little rough with others

4) is original, introduces new ideas

5) often worries

6) can forgive

7) is rather lazy

8) can be outgoing, sociable

9) appreciates artistic, aesthetic experiences

10) gets nervous easily

11) performs tasks effectively and efficiently
12) is reserved

13) is considerate and friendly with others

14) has a vivid imagination, ideas

$15)$ is relaxed, can handle stress well

16) is inquisitive

\section{Page 4-Human Values (optional)}

Q11 In the following, we describe some people to you. Please mark how similar or dissimilar the person described is to you. Please answer using the following scale. The value 1 means: does not apply at all. The value 6 means: fully applies. You can use the values between 1 and 6 to grade your opinion. If you are not sure, please answer with "don't know" in the last column.

o It is important for him/her to develop new ideas and be creative. $\mathrm{He} / \mathrm{she}$ likes to do things in his/her own original way.

o It is important to her/him to be rich. She/he wants to have a lot of money and own expensive things. 
o $\mathrm{He} / \mathrm{she}$ thinks it is important that all people in the world should be treated equally. He/she believes that everyone should have equal opportunities in life.

o It is important for her/him to show his abilities. She/he wants people to admire what she/he does.

o It is important to him/her to live in a safe environment. $\mathrm{He} / \mathrm{she}$ avoids anything that could jeopardize his/her safety.

o She/he likes surprises and is always on the lookout for new activities. She/he thinks that variety is important in life.

o $\mathrm{He} / \mathrm{she}$ thinks that people should do what they are told. $\mathrm{He} / \mathrm{she}$ thinks that people should always follow rules, even when no one sees it.

o It is important to her/him to listen to people who are different from her/him. Even if she/he disagrees with others, she/he still wants to understand them.

o It is important to him/her to be reserved and humble. He/ she tries not to draw attention to himself/herself.

o It is important to her/him to have fun. She/he likes to treat herself/himself.

o It is important to him/her to decide for himself/herself what he/she does. He/she likes to be free and independent of others.

o It is very important to her/him to help the people around her/him. She/he wants to take care of their well-being.

o It is important to him/her to be very successful. He/she hopes that people will recognize his/her achievements.

o It is important to her/him that the state ensures her/his personal safety from all threats. She/he wants a strong state that defends its citizens.

o $\mathrm{He} / \mathrm{she}$ seeks adventure and likes to take risks. He/she wants to have an exciting life.

o It is important to her/him to behave correctly at all times. She/he avoids doing things that other people might think are wrong.

o It is important to him/her that others respect him/her. He/ she wants people to do what he/she says.

o It is important to her/him to be loyal to her/his friends. She/he wants to stand up for people who are close to her/ him.

o $\mathrm{He} /$ she strongly believes that people should take care of nature. Environmental protection is important to him/ her.

o Tradition is important toher/him. She/he tries to adhere to the customs and traditions handed down to her/him by her/his religion or family.

o $\mathrm{He} / \mathrm{she}$ never misses an opportunity to have fun. It is important to him/her to do things that give him/her pleasure.

\section{Page 5-(For owners of an electricity storage)}

Q12 Who in your household had the idea to purchase a solar power storage system?

- Myself

- My partner

- Both together

- Child

- Someone else

- None of us

Q13 Who in your household ultimately made the decision to buy a solar power storage system?

- Myself

- My partner

- Both together

- Child

- Someone else

- None of us

Q14 Why did you decide on a solar storage? (Multiple response).

- The topic of the environment interests me.

- I find that a solar power storage system pays off financially.

- A solar power storage system gives me the feeling of being self-sufficient.

- I am interested in the technology.

Q15 What is the approximate capacity of your solar battery (in $\mathrm{kWh}$ ? [Please select]

- under $1 \mathrm{kWh}$

- $1-2 \mathrm{kWh}$

- $2-3 \mathrm{kWh}$

- $3-4 \mathrm{kWh}$

- 4-5 kWh

- 5-6 kWh

- $6-7 \mathrm{kWh}$

- $7-8 \mathrm{kWh}$

- $8-9 \mathrm{kWh}$

- $9-10 \mathrm{kWh}$

- more than $10 \mathrm{kWh}$

Q16 In which year was your solar storage tank installed? [Please select] 
Q17 How expensive was your solar power storage approximately (incl. installation and VAT)? [Please select]

- less than 2000 Euro

- 2000-under 3000 Euro

- 3000-under 4000 Euro

- 4000-under 5000 Euro

- 5000-under 6000 Euro

- 6000-under 7000 Euro

- 7000-under 8000 Euro

- 8000-under 9000 Euro

- 9000-under 10,000 Euro

- more than 10,000 Euro

Q18 When do you think the investment in the electricity storage system will have paid for itself (in years)? [Please select]

- in less than 5 years

- in 5-6 years

- in 6-7 years

- in 7-8 years

- in 8-9 years

- in 9-10 years

- in 10-11 years

- in $11-12$ years

- in 12-15 years

- in 15-20 years

- in more than 20 years

Q19 How do you personally rate yourself: Are you generally a risk-taker or do you try to avoid risks?

Please answer using the following scale. The value 0 means: not at all willing to take risks. The value 10 means: very willing to take risks.

Q20 Did you have any sense of risk in the following areas because of the purchase of the solar power storage system? Please answer in each case using the following scale. The value 0 means: no feeling of risk. The value 10 means: very strong feeling of risk

- general risk

- financial risk for investments

- risk for my/our health

- risk in trusting other people

\section{Page 6-(for non-owners of an electricity storage)}

Q21 Why did you decide against a solar storage tank? (multiple responses)
- I'm not interested in the environmental issue.

- A solar power storage system is too expensive.

- A solar power storage system is too high a risk for my household.

- The topic was too complicated to make a decision.

Q22 How do you personally rate yourself: Are you generally a risk-taker or do you try to avoid risks? Please answer using the following scale. The value 0 means: not at all willing to take risks. The value 10 means: very willing to take risks.

Q23 Did you have any sense of risk in the following areas because of the purchase of the solar power storage system? Please answer in each case using the following scale. The value 0 means: no feeling of risk. The value 10 means: very strong feeling of risk.

- general risk

- financial risk

- risk to my/our health

- risk in trusting other people

\section{Page 7-Household statistics}

Q23 How many people currently live in your household? [Please select]

- 1

- 2

- 3

- 4

- 5

- 6

- more than 6

Q24 What are the first two digits of your postal code? If you are not from Germany, please enter the license plate number for your country. My postal code starts with the digits ....

Q25 Who writes the shopping list at your house?

- Myself

- My partner

- Both together

- Someone else

- We do not write a shopping list. 
Q26 Who usually goes shopping in your household?

- Myself

- My partner

- Both equally

- Someone else

Q27 Who ultimately decides on major investments (such as consumer electronics, cars, renovations) in your home?

- Myself

- My partner

- Both together

- Someone else

Q28 What is approximately your net monthly household income? This refers to the amount that is made up of the income of all members of the household and that remains after deduction of taxes and social security. [Please select]

- less than $250 €$

- $250 €$ to under $500 €$

- $500 €$ to under $1000 €$

- $1000 €$ to under $1500 €$

- $1500 €$ to under $2000 €$

- $2000 €$ to under $3000 €$

- $3000 €$ to under $4000 €$

- $4000 €$ until under $5000 €$

- $5000 €$ and more

- I do not want to answer

Q29 What are the total household costs (approximately)? This means all costs for, e.g., rent, loans, electricity, water, utilities. [Please select]

- less than $200 €$

- $200 €$ to under $400 €$

- $400 €$ to under $600 €$

- $600 €$ to under $800 €$

- $800 €$ to under $1.000 €$

- $€$ to under $1.200 €$

- $1.200 €$ up to under $1.400 €$

- $1.400 €$ to under $1.600 €$

- $1.600 €$ and more

- I do not want to answer

Q30 In which year were you born?

Q31 What is your gender?
- female

- male

- diverse

Q32 What is your current relationship status?

- Single

- in a committed relationship

- married

- divorced

Q33 What is the highest educational qualification you have?

- Still a student

- Finished school without graduation

- Secondary school diploma (Hauptschulabschluss)

- Secondary school diploma (Mittlere Reife)

- Completion of polytechnic secondary school 10th grade (before 1965: 8th grade)

- Fachhochschulreife (completion of a specialized secondary school)

- Abitur, general or subject-linked higher education entrance qualification (Gymnasium or EOS)

- Other school-leaving qualification:

Q34 Which vocational education degree do you have? Please select the highest educational qualification you have achieved to date

- No vocational training qualification

- Vocational training period with final certificate, but no apprenticeship

- Partial skilled worker qualification

- Completed industrial or agricultural apprenticeship

- Completed commercial apprenticeship

- Professional internship, traineeship

- Vocational school diploma

- Technical school diploma

- Master craftsman, technician or equivalent technical college degree

- University of applied sciences degree

- University degree

- Other degree, namely:

Q35 Are you currently employed?

- Yes, I am employed.

- No, I am unemployed.

- No, I am a pensioner. 
- No, I am a housewife or househusband.

- No, I am none of the above.

Q36 What do you do for a living?

- Student

- In training

- Student

- Salaried employee

- Civil servant

- Self-employed

- Unemployed/looking for work

- Other:

Author's contributions SP analyzed and interpreted the data and was primarily responsible for the drafting of the manuscript. He conducted the statistical analyses and interpreted the findings.

Funding This research did not receive any specific grant from funding agencies in the public, commercial, or not-for-profit sectors.

Data availability Due to privacy restrictions on the part of Facebook, it was not permitted to provide user data. In exceptional cases, the anonymized data can be requested from the corresponding author. Due to data protection restrictions, access to the SOEP data can only be provided to registered users of the SOEP study, available at the Deutsches Institut für Wirtschaftsforschung, Berlin (DIW). Scientific use is free of charge and can be requested at: https://www.diw.de/en/diw_02.c. 222829.en/access_and_ordering.html.

\section{Declarations}

Conflict of interest The author has no competing interests to declare.

Open Access This article is licensed under a Creative Commons Attribution 4.0 International License, which permits use, sharing, adaptation, distribution and reproduction in any medium or format, as long as you give appropriate credit to the original author(s) and the source, provide a link to the Creative Commons licence, and indicate if changes were made. The images or other third party material in this article are included in the article's Creative Commons licence, unless indicated otherwise in a credit line to the material. If material is not included in the article's Creative Commons licence and your intended use is not permitted by statutory regulation or exceeds the permitted use, you will need to obtain permission directly from the copyright holder. To view a copy of this licence, visit http://creativecommons.org/licenses/by/4.0/.

\section{References}

Aral S, Walker D (2012) Identifying influential and susceptible members of social networks. Science 337:337-341. https://doi.org/10. $1126 /$ science. 1215842

Ashton MC, Lee K (2007) Empirical, theoretical, and practical advantages of the HEXACO model of personality structure. Pers Soc
Psychol Rev 11:150-166. https://doi.org/10.1177/1088868306 294907

Ashton MC, Lee K (2009) The HEXACO-60: a short measure of the major dimensions of personality. J Pers Assess 91:340-345. https://doi.org/10.1080/00223890902935878

Ashton MC, Lee K, Perugini M, Szarota P, de Vries RE, Di Blas L, Boies K, de Raad B (2004) A six-factor structure of personalitydescriptive adjectives: solutions from psycholexical studies in seven languages. J Pers Soc Psychol 86:356-366. https://doi.org/ 10.1037/0022-3514.86.2.356

Banks M (1996) Ethnicity: anthropological constructions. Routledge, London

Barrett PT, Petrides KV, Eysenck SBG, Eysenck HJ (1998) The Eysenck Personality Questionnaire: an examination of the factorial similarity of $\mathrm{P}, \mathrm{E}, \mathrm{N}$, and $\mathrm{L}$ across 34 countries. Person Individ Differ 25:805-819. https://doi.org/10.1016/S0191-8869(98) 00026-9

Benet-Martínez V, John OP (1998) Los Cinco Grandes across cultures and ethnic groups: multitrait-multimethod analyses of the Big Five in Spanish and English. J Pers Soc Psychol 75:729-750. https:// doi.org/10.1037//0022-3514.75.3.729

Bilsky W, Schwartz SH (1994) Values and personality. Eur J Pers 8:163-181. https://doi.org/10.1002/per.2410080303

Busic-Sontic A, Brick C (2018) Personality trait effects on green household installations. Collabra Psychol 4:8. https://doi.org/ 10.1525/collabra. 120

Cieciuch J, Schwartz SH (2017) Values. In: Zeigler-Hill V, Shackelford TK (eds) Encyclopedia of personality and individual differences, vol 26. Springer, Cham, pp 1-5

Costa PT (1996) Work and personality: use of the NEO-PI-R in industrial/organisational psychology. Appl Psychol 45:225-241. https://doi.org/10.1111/j.1464-0597.1996.tb00766.x

Costa PT, McCrae RR (1976) Age differences in personality structure: a cluster analytic approach. J Gerontol 31:564-570

Costa PT, McCrae RR (2008) The revised NEO personality inventory (NEO-PI-R). In: Boyle GJ, Matthews G, Saklofske DH (eds) The SAGE handbook of personality theory and assessment: personality measurement and testing (volume 2), 1st edn. Sage Publications Ltd, London, pp 179-198

DIW Berlin (2007) DIW Berlin: Über uns. http://www.diw.de/de/ diw_02.c.221178.de/ueber_uns.html\#299767. Accessed 13 May 2018

Danielsbacka M, Tanskanen AO, Billari FC (2019) Who meets online? Personality traits and sociodemographic characteristics associated with online partnering in Germany. Person Individ Differ 143:139-144. https://doi.org/10.1016/j.paid.2019.02.024

Das AS, Datar M, Garg A, Rajaram S (2007) Google news personalization. In: Williamson C, Zurko ME, Patel-Schneider P, Shenoy P (eds) Proceedings of the 16th international conference on World Wide Web-WWW '07. ACM Press, New York, p 271

Dehne M, Schupp J (2007) Persönlichkeitsmerkmale im Sozio-oekonomischen Panel (SOEP) - Konzept, Umsetzung und empirische Eigenschaften. https://www.diw.de/de/diw_01.c.451462.de/publi kationen/research_notes/2007_0026/persoenlichkeitsmerkmale_ im_sozio-oekonomischen_panel_soep__konzept_umsetzung_ und_empirische_eigenschaften.html. Accessed 18 Aug 2021

DeYoung CG (2015) Cybernetic Big Five theory. J Res Pers 56:33-58. https://doi.org/10.1016/j.jrp.2014.07.004

Feldesman MR (2002) Classification trees as an alternative to linear discriminant analysis. Am J Phys Anthropol 119:257-275. https:// doi.org/10.1002/ajpa.10102

Fischer R (2018) Personality, values, culture: an evolutionary approach. Culture and psychology. Cambridge University Press, Cambridge

Goebel J, Grabka MM, Liebig S, Kroh M, Richter D, Schröder C, Schupp J (2019) The German socio-economic panel (SOEP). 
Jahrbücher Für Nationalökonomie Und Statistik 239:345-360. https://doi.org/10.1515/jbnst-2018-0022

Goldberg LR (1993) The structure of phenotypic personality traits. Am Psychol 48:26-34. https://doi.org/10.1037/0003-066X.48.1.26

Goldberg LR, Johnson JA, Eber HW, Hogan R, Ashton MC, Cloninger CR, Gough HG (2006) The international personality item pool and the future of public-domain personality measures. J Res Pers 40:84-97. https://doi.org/10.1016/j.jrp.2005.08.007

González RJ (2017) Hacking the citizenry? Personality profiling, 'big data' and the election of Donald Trump. Anthropol Today 33:912. https://doi.org/10.1111/1467-8322.12348

Jacksohn A, Grösche P, Rehdanz K, Schröder C (2019) Drivers of renewable technology adoption in the household sector. Energy Econ 81:216-226. https://doi.org/10.1016/j.eneco.2019.04.001

John OP, Naumann LP, Soto CJ (2010) Paradigm shift to the integrative Big Five taxonomy: history, measurement, and conceptual issues. In: John OP, Robins RW, Pervin LA (eds) Handbook of personality: theory and research. Guilford Press, New York, pp 114-158

Kosinski M (2021) Facial recognition technology can expose political orientation from naturalistic facial images. Sci Rep 11:100. https://doi.org/10.1038/s41598-020-79310-1

Kosinski M, Stillwell DJ, Graepel T (2013) Private traits and attributes are predictable from digital records of human behavior. Proc Natl Acad Sci USA 110:5802-5805. https://doi.org/10.1073/pnas. 1218772110

Kosinski M, Wang Y, Lakkaraju H, Leskovec J (2016) Mining big data to extract patterns and predict real-life outcomes. Psychol Methods 21:493-506. https://doi.org/10.1037/met0000105

Kosinski M, Stillwell DJ, Popov V, Kielczewski B (2019) Apply Magic Sauce-Prediction API. https://applymagicsauce.com/about-us. Accessed 25 July 2019

Lambiotte R, Kosinski M (2014) Tracking the digital footprints of personality. Proc IEEE 102:1934-1939. https://doi.org/10.1109/ JPROC.2014.2359054

Liebig S, Schupp J, Goebel J, Richter D, Schröder C, Bartels C, Fedorets A, Franken A, Giesselmann M, Grabka MM, Jacobsen J, Kara S, Krause P, Kröger H, Kroh M, Metzing M, Nebelin J, Schacht D, Schmelzer P, Schmitt C, Schnitzlein D, Siegers R, Wenzig K, Zimmermann S, Deutsches Institut für Wirtschaftsforschung e.V. (2019) Socio-Economic Panel (SOEP), data for years 1984-2018. https://www.diw.de/sixcms/detail.php?id=diw_ 01.c.742256.en. Accessed 18 Aug 2021

Marengo D, Sindermann C, Elhai JD, Montag C (2020) One social media company to rule them all: associations between use of Facebook-owned social media platforms, sociodemographic characteristics, and the Big Five personality traits. Front Psychol 11:936. https://doi.org/10.3389/fpsyg.2020.00936

Marouf AA, Hasan MK, Mahmud H (2020a) Comparative analysis of feature selection algorithms for computational personality prediction from social media. IEEE Trans Comput Soc Syst 7:587-599. https://doi.org/10.1109/TCSS.2020.2966910

Marouf AA, Hasan MK, Mahmud H (2020b) Secret life of conjunctions: correlation of conjunction words on predicting personality traits from social media using user-generated contents. In: Sengodan T, Murugappan M, Misra S (eds) Advances in electrical and computer technologies: select proceedings of ICAECT 2019, vol 672. Springer, Singapore, pp 513-525

McCrae RR, Costa PT (1997) Personality trait structure as a human universal. Am Psychol 52:509-516

McCrae RR, Costa PT (1999) A five-factor theory of personality. In: Pervin LA, John OP (eds) Handbook of personality: theory and research, 2nd edn. Guilford Press, New York, pp 139-153
McCrae RR, Costa PT (2004) A contemplated revision of the NEO five-factor inventory. Person Individ Differ 36:587-596. https:// doi.org/10.1016/S0191-8869(03)00118-1

McCrae RR, John OP (1992) An introduction to the five-factor model and its applications. J Pers 60:175-215. https://doi.org/10.1111/j. 1467-6494.1992.tb00970.x

Merenda PF (1987) Toward a four-factor theory of temperament and/ or personality. J Pers Assess 51:367-374. https://doi.org/10.1207/ s15327752jpa5103_4

Parish L, Eysenck HJ, Eysenck SGB (1965) The eysenck personality inventory. Br J Educ Stud 14:140. https://doi.org/10.2307/31190 50

Poier S (2021) Towards a psychology of solar energy: analyzing the effects of the Big Five personality traits on household solar energy adoption in Germany. Energy Res Soc Sci 77:102087. https://doi. org/10.1016/j.erss.2021.102087

Popov V, Gosling SD, Kosinski M, Matz SC, Stillwell DJ (2015) Facebook as a research tool for the social sciences: opportunities, challenges, ethical considerations, and practical guidelines. Am Psychol 70:543-556. https://doi.org/10.1037/a0039210

Rozgonjuk D, Sindermann C, Elhai JD, Montag C (2021) Individual differences in fear of missing out (FoMO): age, gender, and the Big Five personality trait domains, facets, and items. Person Individ Differ 171:110546. https://doi.org/10.1016/j.paid.2020. 110546

Schwartz SH (2017) Schwartz, Shalom. In: Zeigler-Hill V, Shackelford TK (eds) Encyclopedia of personality and individual differences, vol 15. Springer, Cham, pp 1-3

Segalin C, Celli F, Polonio L, Kosinski M, Stillwell D, Sebe N, Cristani M, Lepri B (2017) What your Facebook profile picture reveals about your personality. In: Liu Q, Lienhart R, Wang H, Chen S-WK-T, Boll S, Chen P, Friedland G, Li J, Yan S (eds) MM'17: Proceedings of the 2017 ACM multimedia conference: October 23-27, 2017, Amsterdam, the Netherlands. ACM Association for Computing Machinery, New York, pp 460-468

Smith ML, Hamplová D, Kelley J, Evans MDR (2021) Concise survey measures for the Big Five personality traits. Res Soc Stratific Mob 73:100595. https://doi.org/10.1016/j.rssm.2021.100595

Soto CJ, John OP (2017) The next Big Five inventory (BFI-2): developing and assessing a hierarchical model with 15 facets to enhance bandwidth, fidelity, and predictive power. J Pers Soc Psychol 113:117-143. https://doi.org/10.1037/pspp0000096

Stillwell DJ, Kosinski M (2019) myPersonality.org. https://sites.google. com/michalkosinski.com/mypersonality/home. Accessed 25 July 2019

Valchev VH, van de Vijver FJR, Nel JA, Rothmann S, Meiring D (2013) The use of traits and contextual information in free personality descriptions across ethnocultural groups in South Africa. J Pers Soc Psychol 104:1077-1091. https://doi.org/10.1037/a0032 276

Youyou W, Kosinski M, Stillwell DJ (2015) Computer-based personality judgments are more accurate than those made by humans. Proc Natl Acad Sci USA 112:1036-1040. https://doi.org/10.1073/ pnas. 1418680112

Zhang Z, Yao X, Yuan S, Deng Y, Guo C (2021) Big Five personality influences trajectories of information seeking behavior. Person Individ Differ 173:110631. https://doi.org/10.1016/j.paid.2021. 110631

Publisher's Note Springer Nature remains neutral with regard to jurisdictional claims in published maps and institutional affiliations. 